\title{
THE EFFECTS OF VEHICLE LOAD ON DRIVING CHARACTERISTICS
}

\author{
Vladimir Rievaj', Ján Vrábel', František Synák', Ladislav Bartuška² \\ 1 University of Zilina, The Faculty of Operation and Economics of Transport and Communications, Univerzitna 1, \\ 010 26, Zilina, Slovak Repulic, e-mail: rievaj@fpedas.uniza.sk, vrabel@fpedas.uniza.sk, synak@fpedas.uniza.sk \\ 2 The Institute of Technology and Business, Department of Transport and Logistics, Okruzni 517/10, \\ 37001 České Budejovice, Czech Republic, e-mail: bartuska@mail.vstecb.cz
}

Received: 2017.11.29

Accepted: 2018.02.01

Published: 2018.03.01

\begin{abstract}
Many traffic accidents are due to an incorrect assessment of the current situation by the driver of the vehicle. With correct assessment of the situation, the driver has also to take into account a number of other factors. This article focuses on some of these factors such as the vehicle load, vehicle speed and curve radius. The first part of the article deals with the position of the vehicle center of gravity (CG), which has a major impact on the driving characteritics of the vehicle. The paper demonstrates the calculation of the maximum speed of a car model and truck model (without load and with load) when cornering. The center of gravity has an effect on the vehicle axles load distribution, and thereby on braking forces. This issue is dealt with in the second part of the paper. In the last part the calculation of the braking force as a function of the adhesion coefficient of the tires depending on the road surface is mentioned. The importance of the contribution consists in quantifying the impact of vehicle load on its driving characteristics.
\end{abstract}

Keywords: gravity center of vehicle, road curve radius, speed at passage, directional deviation, vehicle stability

\section{INTRODUCTION}

Road accidents and their consequences due to technical progress show a decreasing tendency. Even unfavorable figures do not discourage us from driving motor vehicles [11]. There are also drivers who drive in high speed on the problematic road section where was a serious accident in the past, thinking they can always avoid an accident because of their experience[12]. Many of them, however, do not realize that the driving characteristics of the vehicle in operation are changed [9]. Surface quality of the road that the vehicle is moving along, ambient temperature, or technical condition of the vehicle have an impact on changing the vehicle driving characteristics[25]. The vehicle load and load distribution have significant influence because they change the center of gravity towards individual axles and its height above the road surface [6]. With wheel load the angle of directional deviation changes as well having a significant impact on the driving characteristics of the vehicle [7].

\section{INFLUENCE OF HEIGHT OF THE CENTRE OF GRAVITY ABOVE THE ROAD SURFACE}

The centre of gravity position affects the distribution of weight between the individual wheels when cornering. It also significantly affects the magnitude of the heeling moment caused by centrifugal force [24]. The maximum safe speed can be estimated based on simplifying assumptions [14]. Let's assume that the vehicle is cornering at a constant speed. The effects of rolling and wind resistance are neglected as their magnitude is small compared to the mag- 
nitude of the centrifugal force. A common passenger car of a weight of $1200 \mathrm{~kg}$, when passing curves with the radius of $100 \mathrm{~m}$ at a speed of $90 \mathrm{kmph}$, reaches the centrifugal force of 7500 $\mathrm{N}$, where the rolling resistance is $130 \mathrm{~N}$ and wind resistance $255 \mathrm{~N}$. For simplification, let's assume that lateral wheel deformation does not occur [1]. At this moment, it is possible to determine the maximum safe speed for cornering. In the vehicle centre of gravity dextral coordinates system will be placed and individual forces applied on the vehicle will be marked (see Figure 1).

There are two situations compared:

The vehicle is sufficiently overturning resistant; therefore only the sum of the forces acting in the axial direction Y [23], (see Figure 1). For this case, the following equation must be valid:

$$
F_{Y}^{\prime}+F_{Y}^{\prime \prime}=F_{o} \cdot \cos \alpha-G \cdot \sin \alpha
$$

By solving this equation, the equation for determining the maximum speed of the vehicle when passing the curve at the skid speed limit [20] will arise:

$$
V=3,6 \cdot \sqrt{R \cdot g \cdot \frac{\mu+\operatorname{tg} \alpha}{1-\mu \cdot \operatorname{tg} \alpha}}
$$

The speed thus calculated is subsequently compared with the speed calculated regarding that the road grip of the wheels is so high that as a result of the forces acting in the axial direction $\mathrm{Y}$, the vehicle will not get into skid, but will tend to overturn around the point 1 [23]. In that case, the following equation must be valid:

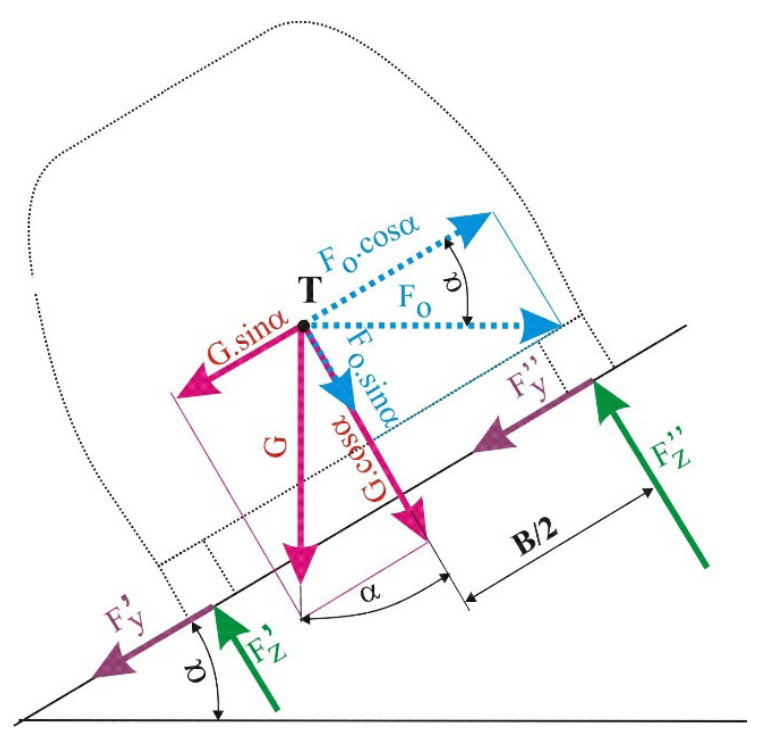

Fig. 1 Forces applied to vehicle passing sloped curve [23]

$$
\begin{gathered}
G \cdot \sin \alpha \cdot h_{t}+G \cdot \cos \alpha \cdot \frac{B}{2}- \\
-F_{o} \cdot \cos \alpha \cdot h_{t}+F_{o} \cdot \frac{B}{2} \cdot \sin \alpha=0
\end{gathered}
$$

By solving this equation, the equation for calculating the maximum speed of the vehicle when passing the curve at the overturning speed limit according to 10$]$ :

$$
V=3,6 \cdot \sqrt{R \cdot g \cdot \frac{2 \cdot h_{t} \cdot \operatorname{tg} \alpha+B}{2 \cdot h_{t}-B \cdot \operatorname{tg} \alpha}}
$$

where: $V$ is speed limit [kmph],

$R$ is curve radius [m],

$g$ is acceleration due to the gravity $\left[\mathrm{m} \cdot \mathrm{s}^{-2}\right]$, $\mu$ is adhesion coefficient [-],

$\alpha$ is the road slope in the curve $\left[^{\circ}\right]$, transverse gradient of the road,

$h_{t}$ is the height of the centre of gravity [m], $B$ is the vehicle wheel track [m].

For determining the maximum speed at which the vehicle can pass the curve with a specific radius, it is necessary to determine the maximum speed at the overturning speed limit and subsequently the skid speed limit. The lower value becomes a constraining factor [7]. Table 1 shows the maximum speed when passing curves with different radius for a vehicle with the following parameters:

Height of centre of gravity $h_{t}=0.7 \mathrm{~m}$, transverse gradient of the road in the curve $\alpha=3 \%$, vehicle wheel track $\mathrm{B}=1.45 \mathrm{~m}$, lateral adhesion of wheels $\mu_{\mathrm{y}}=0.8$.

The question is show theses values change for a vehicle of a weight of $1200 \mathrm{~kg}$ with a $70-\mathrm{kg}$ roof rack, with a centre of gravity at the height of $1600 \mathrm{~mm}$ above the road surface. For a vehicle with such load, the height of the centre of gravity above the road surface will increase from $0.7 \mathrm{~m}$ to $0.75 \mathrm{~m}$. The new values of the maximum speed for cornering are showed in Table 2.

As seen from Table 2, the maximum speed values at a limit of overturning approaches to the values at the limit of skid. The change of the position of the centre of gravity for trucks/goods vehicles will show higher dependency on the load, since their payload is comparable or higher than the weight of the vehicle [26]. This naturally causes that the overturning speed limit can be lower than the skid speed limit [11]. A comparison was carried out for a vehicle of the weight of $\mathrm{m}_{\mathrm{v}}=8000 \mathrm{~kg}$, the load capacity of the vehicle $\mathrm{m}_{\mathrm{u}}$ $=8000 \mathrm{~kg}$ and the following parameters: 
Table 1. Influence of the curve radius on the passing speed

\begin{tabular}{|l|c|c|c|c|c|c|}
\hline Curve radius $[\mathrm{m}]$ & 50 & 100 & 150 & 200 & 250 & 300 \\
\hline $\mathrm{V}_{\text {skid }}[\mathrm{kmph}]$ & 73.5 & 104.0 & 127.3 & 147.0 & 164.4 & 180.1 \\
\hline $\mathrm{V}_{\text {overturning }}[\mathrm{kmph}]$ & 83.6 & 118.2 & 144.8 & 167.2 & 186.9 & 204.8 \\
\hline
\end{tabular}

Table 2. Influence of the curve radius on the passing speed

\begin{tabular}{|l|c|c|c|c|c|c|}
\hline Curve radius $[\mathrm{m}]$ & 50 & 100 & 150 & 200 & 250 & 300 \\
\hline $\mathrm{V}_{\text {skid }}[\mathrm{kmph}]$ & 73.5 & 104.0 & 127.3 & 147.0 & 164.4 & 180.1 \\
\hline $\mathrm{V}_{\text {overturning }}[\mathrm{kmph}]$ & 80.8 & 114.2 & 139.9 & 161.5 & 180.6 & 197.8 \\
\hline
\end{tabular}

The height of the centre of gravity of an empty vehicle $h_{t}=1.0 \mathrm{~m}$, the height of the centre of gravity of loaded vehicle $\mathrm{h}_{\mathrm{tN}}=1.5 \mathrm{~m}$, road slope in the curve $\alpha=3 \%$, vehicle wheel track a B $=2.1$ $\mathrm{m}$, adhesion coefficient $\mu=0.8$. The results are showed in Table 3.

\section{TURNING CIRCLE RADIUS}

According to Ackerman's theory (see Figure 2), assuming that the vehicle passes through a curve with a large radius at a low speed, so the vehicle is not affected by centrifugal forces and the vehicle wheels show no directional deviation, the axes of wheels rotation intersect at one point at the axis of the rear axle. This is a condition for the vehicle wheels to roll on the road surface and do not show any lateral shift [9]. With a rotation of the outside front wheel by angle $\beta_{1}=$ $2.934^{\circ}$ the vehicle turning radius is $50 \mathrm{~m}$.

When passing the curve, the vehicle will be under the influence of centrifugal forces [17]. This causes different wheel load. The real wheels with lateral load show a specific directional deviation [8]. In such case, the condition for the validity of Ackerman's theory is not fulfilled and the actual turning radius of the vehicle will be different. The actual turning radius of the vehicle can be calculated using the following equation [5]:

$$
R_{s}=\frac{L-\frac{B}{2} \cdot \operatorname{tg}\left(\beta_{1}-\alpha_{1}\right)}{\operatorname{tg}\left(\beta_{1}-\alpha_{1}\right)+\operatorname{tg} \alpha_{z}}
$$

where $L$ is the distance of axles [m],

$\beta_{1}$ is the steering angle of the outside front wheel $\left[^{\circ}\right]$,

$\alpha_{1}$ is the directional deviation angle of the outside front wheels $\left[{ }^{\circ}\right]$,

$\alpha_{z}$ is an average value of the directional deviation angle of the outside rear wheels $\left[^{\circ}\right]$.

To compare the theoretical and actual turning radius, the steering angle of the outside wheel will be $\beta_{1}=2.934^{\circ}$. Theoretically, the vehicle passes the curve with the radius of $50 \mathrm{~m}$. Now the directional deviation angles of individual wheels need to be determined. These change according to the wheel load $F_{z}$ lateral force $F_{y}[9]$ (see Figure 3).

The distance between the centre of gravity and the front axle $\mathrm{L}_{1}=1.2 \mathrm{~m}$ and between the centre of gravity and the rear axle $\mathrm{L}_{2}=1.4 \mathrm{~m}$. The maximum safety speed of a passenger car for passing the curve at the skid speed limit is $73.5 \mathrm{kmph}$ according to Table 1.

With some safety reserve, drivers are recommended to pass the curve at the speed of $40 \mathrm{kmph}$ [15]. The magnitude of centrifugal force acting at the centre of gravity of the vehicle $\mathrm{F}_{\mathrm{o}}$ is calculated as follows:

$$
F_{o}=\frac{m \cdot V^{2}}{3.6^{2} \cdot R}
$$

where: $m$ is the weight of the vehicle [1200 kg], $V$ is the vehicle speed [kmph], $R$ is the curve radius [m].

Table 3. Influence of the curve radius on the passing speed for a goods vehicle

\begin{tabular}{|l|c|c|c|c|c|c|}
\hline Curve radius $[\mathrm{m}]$ & 50 & 100 & 150 & 200 & 250 & 300 \\
\hline $\mathrm{V}_{\text {skid }}[\mathrm{kmph}]$ & 73.5 & 104.0 & 127.3 & 147.0 & 164.4 & 180.1 \\
\hline $\mathrm{V}_{\text {overturning }}$ pre $\mathrm{h}_{\mathrm{t}}=1 \mathrm{~m}[\mathrm{kmph}]$ & 84.8 & 119.9 & 146.9 & 169.6 & 189.6 & 207.7 \\
\hline $\mathrm{V}_{\text {overtirmomg }}$ pre $\mathrm{h}_{\mathrm{t}}=1.5 \mathrm{~m}[\mathrm{kmph}]$ & 69.3 & 98.0 & 120.1 & 138.6 & 155.0 & 169.8 \\
\hline
\end{tabular}




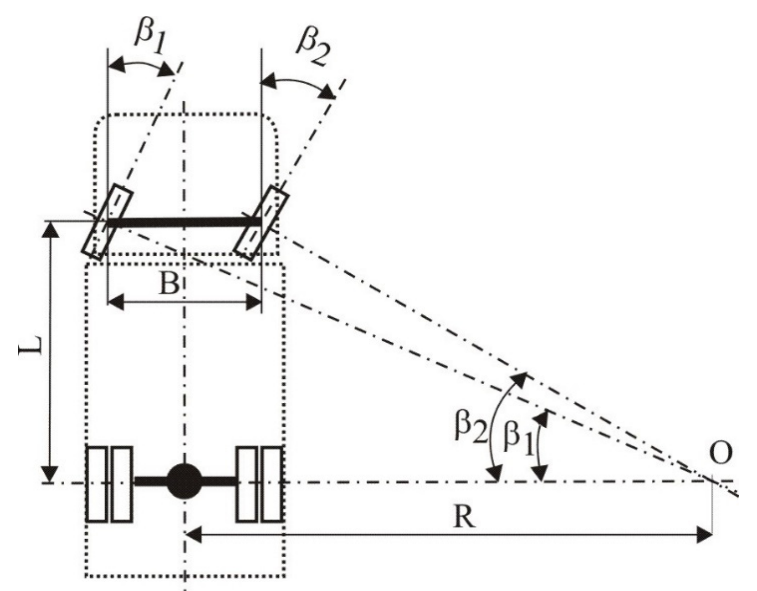

Fig. 2 Turning circle radius according to Ackerman's theory [22]

Magnitude of centrifugal force is:

$$
F_{o}=\frac{1200 \cdot 40^{2}}{3.6^{2} \cdot 50}=2962.9 \mathrm{~N}
$$

Forces acting on individual axles can be calculated by application of sine law for non-rightangled triangles [11] (see Figure 3). The individual angles are determined according to Figure 3 :

$$
\begin{aligned}
& \operatorname{tg} \delta=\frac{L}{R}=\frac{2.6}{50}=0.052 \Rightarrow \delta=2.977^{\circ} \\
& \operatorname{tg} \gamma=\frac{L_{2}}{R}=\frac{1.4}{50}=0.028 \Rightarrow \gamma=1.604^{\circ} \\
& \varepsilon=\delta-\gamma=2.977-1.604=1.373^{\circ} \\
& \eta=180-\varepsilon-\gamma=180-1.373-1.604=177.023^{\circ}
\end{aligned}
$$

By application of the sine law, for calculating $\mathrm{F}_{1}$ force is valid that:

$$
F_{1}=\frac{F_{O} \cdot \sin \gamma}{\sin \eta}=\frac{2962.9 \cdot \sin \left(1.602^{\circ}\right)}{\sin \left(177.023^{\circ}\right)}=1594.9 \mathrm{~N}
$$

whereas for calculating $\mathrm{F}_{2}$ force, it holds true that:

$$
F_{2}=\frac{F_{O} \cdot \sin \varepsilon}{\sin \eta}=\frac{2962.9 \cdot \sin \left(1.373^{\circ}\right)}{\sin \left(177.023^{\circ}\right)}=1367.0 \mathrm{~N}
$$

For determining the wheels load for the front axle it is assumed that the centre of mass $m_{1}=$ $646 \mathrm{~kg}$, which falls on the front axle, is at the same height above the road surface as the centre of gravity of the vehicle and is located in the centre of the axle. The same assumption will apply for $\mathrm{m}_{2}=554 \mathrm{~kg}$, which is the weight falling on the rear axle. The subscripts 1 are assigned to the front axle, subscript 2 to the rear axle. Superscripts 1 signify the outside wheel, $\mathrm{P}$ means inside wheel.

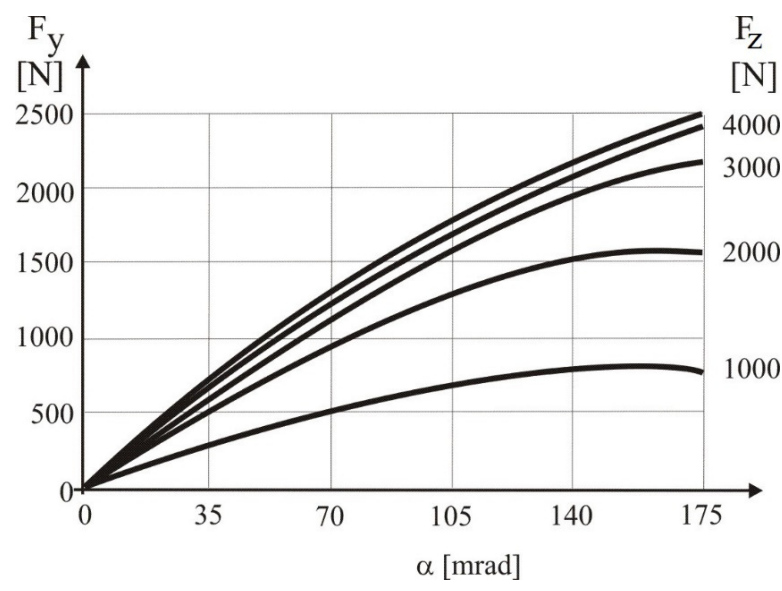

Fig. 3 Directional deviation angle of wheel [22]

According to the figures above it was possible to determine the wheel load for the front inside wheel:

$$
\begin{aligned}
& R_{z 2}^{p}=\frac{G_{2} \cdot \frac{B}{2}-F_{2} \cdot h_{t}}{B}= \\
& =\frac{554 \cdot 9.81 \cdot \frac{1.45}{2}-1367 \cdot 0.7}{1.45}=2057.4 \mathrm{~N}
\end{aligned}
$$

As well as for the front outside wheel:

$$
R_{z 1}^{l}=G_{1}-R_{z 1}^{p}=3938.4 N
$$

Similar procedure will be applied in case of the rear axle.

$$
R_{z 2}^{l}=G_{2}-R_{z 2}^{p}=3377.3 N
$$

It should be also supposed that the transmission of the lateral force will be ensured by wheels proportionately to their weight. The individual wheels will then capture the following force:

$$
\begin{aligned}
F_{y 1}^{p} & =\frac{F_{1}}{G_{1}} \cdot R_{z 1}^{p}=\frac{1594.5}{646 \cdot 9.81} \cdot 2398.9=603.6 \mathrm{~N} \\
F_{y 1}^{l} & =F_{1}-F_{y 1}^{p}=1594.5-603.6=990.9 \mathrm{~N} \\
F_{y 2}^{p} & =\frac{F_{2}}{G_{2}} \cdot R_{z 2}^{p}=\frac{1367}{554 \cdot 9.81} \cdot 2057.4=517.5 \mathrm{~N} \\
F_{y 2}^{l} & =F_{2}-F_{y 2}^{p}=1367-517.5=849.5 \mathrm{~N}
\end{aligned}
$$

Based on the load and the magnitude of the lateral force it is possible to identify the angle of the directional deviation of the individual wheels [23]: 

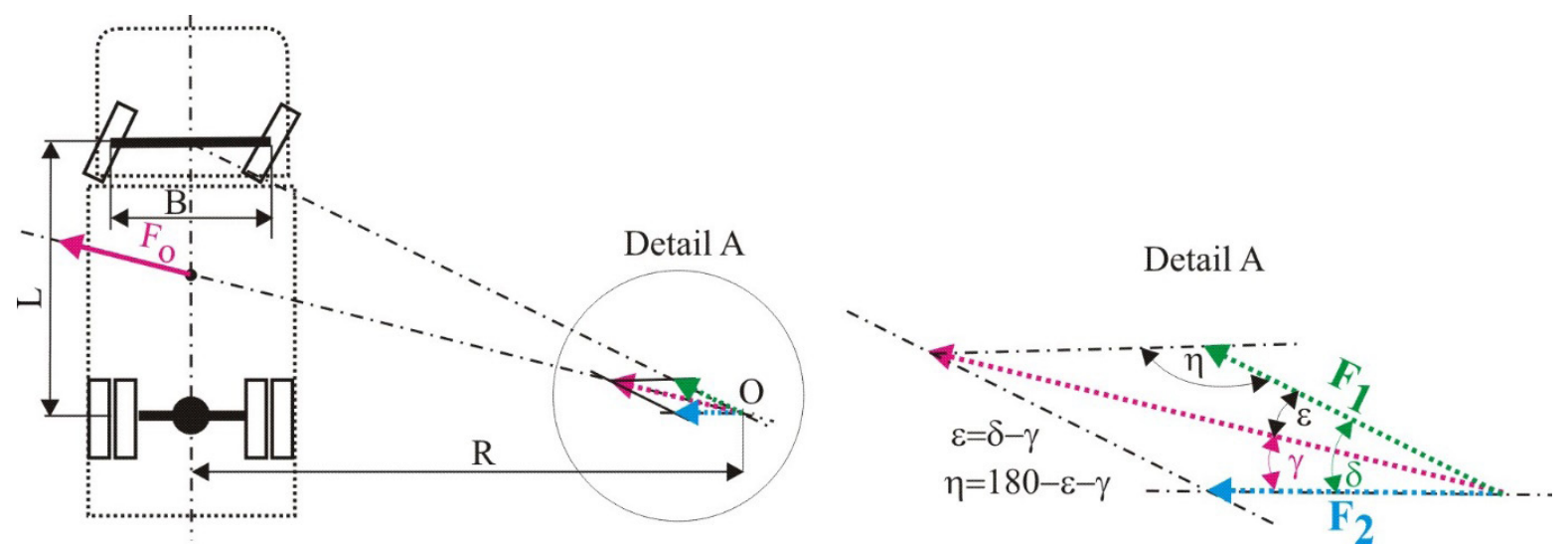

Fig. 4 Determining the size of forces F1 and F2 acting on the axles [21]

$$
\begin{aligned}
& \alpha_{1}^{l}=2.965^{\circ} \\
& \alpha_{1}^{p}=2.177^{\circ} \\
& \alpha_{2}^{l}=2.292^{\circ} \\
& \alpha_{2}^{p}=2.005^{\circ} \\
& \alpha_{z}=2.149^{\circ}
\end{aligned}
$$

At this moment, it is possible to determine / calculate the actual turning ratio of the vehicle:

$$
\begin{aligned}
& R_{s}=\frac{L-\frac{B}{2} \cdot \operatorname{tg}\left(\beta_{1}-\alpha_{1}\right)}{\operatorname{tg}\left(\beta_{1}-\alpha_{1}\right)+\operatorname{tg} \alpha_{z}}= \\
& =\frac{2.6-\frac{1.45}{2} \cdot \operatorname{tg}(2.934-2.965)}{\operatorname{tg}(2.934-2.965)+\operatorname{tg} 2.149}=70.3 \mathrm{~m}
\end{aligned}
$$

The vehicle is understeered.

How will the vehicle behavior change in case of placing a rack on its roof, which causes that the height of the center of gravity is increased to $0.75 \mathrm{~m}$ ? By applying exactly the same procedure it is possible to identify the actual turning circle radius of the vehicle. Due to the location of the

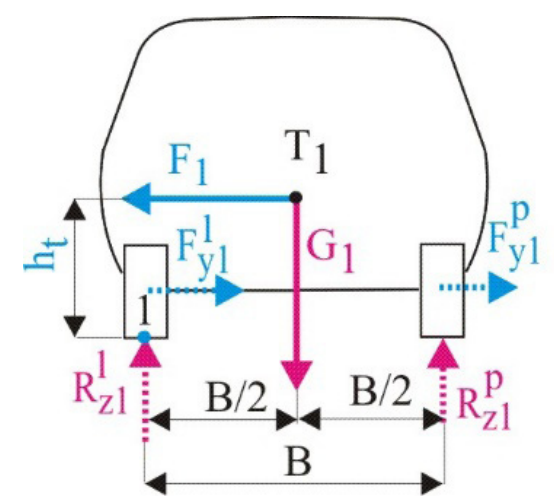

roof rack, the total weight of the vehicle is increased, and the individual wheels load as well as the transmitted lateral forces have changed [22]. The new value of the actual turning circle radius can be calculated as follows:

$$
\begin{aligned}
& R_{s}=\frac{L-\frac{B}{2} \cdot \operatorname{tg}\left(\beta_{1}-\alpha_{1}\right)}{\operatorname{tg}\left(\beta_{1}-\alpha_{1}\right)+\operatorname{tg} \alpha_{z}}= \\
& =\frac{2.6-\frac{1.45}{2} \cdot \operatorname{tg}(2.934-3.438)}{\operatorname{tg}(2.934-3.438)+\operatorname{tg} 2.349}=80.9 \mathrm{~m}
\end{aligned}
$$

Change of the position of the center of gravity has caused deterioration of vehicle understeer and the actual turning circle radius has increased.

\section{BRAKING PROCESS}

CG position also affects the axle load and hence the magnitude of braking forces that are transmitted by the wheels on each axle [15]. According to Mockor [19], it is possible to calculate the percentage share of the braking forces on the axles using the following equation:

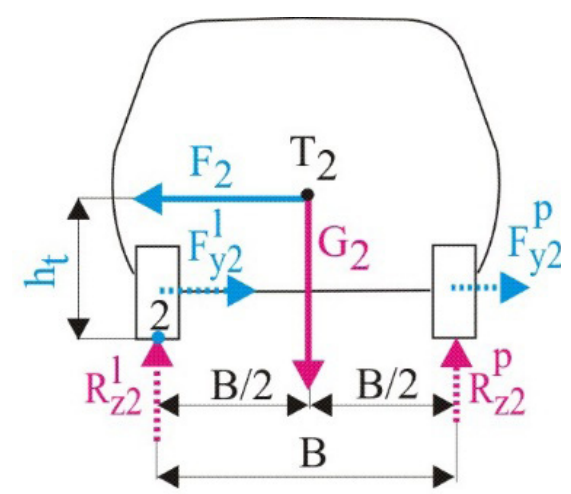

Fig. 5 Determining the load for individual wheels [11] 


$$
\frac{K_{b 1}}{K_{b 2}}=\frac{\lambda_{2}+\lambda_{t} \cdot\left(\mu_{x}+f\right)}{\lambda_{1}-\lambda_{t} \cdot\left(\mu_{x}+f\right)}
$$

where $K_{b 1}, K_{b 2}$ is braking force percentage out of total braking force (front and rear axles), $\lambda_{1}$ is calculated as a quotient of the distance of the CG from the front axle and Wheel Base,

$\lambda_{2}$ is calculated as a quotient of the distance of the CG from the rear axle and Wheel Base,

$\lambda_{t}$ is calculated as a quotient of the height of the CG above a flat surface from the Wheel Base,

$f$ is the coefficient of rolling resistance, $\mu_{x}$ is the coefficient of adhesion between tires and road surface in the direction of the $\mathrm{X}$ axis.

Table 4 gives an overview of changes in the magnitude of the braking force depending on the distance between the center of gravity and the front axle.

A significant impact of the distance of the center of gravity from each axle is evident from the table. Trucks are significantly much more susceptible to changes of CG position [5] because their payload is comparable with a curb weight of the vehicle and the cargo is placed over the rear axle [4].
The height of center of gravity above the flat road surface affects the distribution of braking forces as well [3]. Table 5 provides an overview of changes in the proportion of the braking forces at a constant distance of the center of gravity from each axle depending on the height of the center of gravity changes.

Again, it can be assumed that there will be significant impact on trucks, because the center of gravity of the laden vehicle will be significantly higher than the CG of the empty vehicle [2].

The braking forces are affected by the adhesion coefficient between tires and road surface as well [9]. Typical values of adhesion coefficient $\mu$ for different surfaces are shown in Table 6 .

The effect of the adhesion coefficient of tires on the distribution of the braking forces is demonstrated in Table 7. The change is calculated for a constant distance of center of gravity from axles $\mathrm{L}_{1}=1.2 \mathrm{~m}, \mathrm{~L}_{2}=1.4 \mathrm{~m}$ and for the height of the $\mathrm{CG} \mathrm{h}_{\mathrm{t}}=0.7$.

As shown in Table 7, the value of the adhesion coefficient has a significant impact on the distribution of the braking forces as well [18]. The individual results show that there is an advantage in using such braking systems, which can affect the braking forces depending on the load [10], or which can use brake possibilities independently on each wheel [13].

Table 4. Change in the magnitude of braking forces (in percentage) at the front and rear axles depending on the distance of the CG from each axle using $\mu \mathrm{x}=0.8$ and $\mathrm{f}=0.011$

\begin{tabular}{|l|l|c|c|c|c|c|}
\hline \multirow{3}{*}{$\begin{array}{l}\text { Distance of center of gravity } \\
{\left[\begin{array}{l}\mathrm{m}] \\
\end{array}\right.}\end{array}$} & from the front axle $\mathrm{L}_{1}$ & 1.1 & 1.2 & 1.3 & 1.4 & 1.5 \\
\cline { 2 - 7 } & from the rear axle $\mathrm{L}_{2}$ & 1.5 & 1.4 & 1.3 & 1.2 & 1.1 \\
\cline { 2 - 7 } & $\begin{array}{l}\text { above the flat road surface } \\
\mathrm{h}_{\mathrm{t}}\end{array}$ & \multicolumn{4}{|l|}{0.7} & \multicolumn{4}{|l|}{} \\
\hline $\begin{array}{l}\text { Percentage from the total } \\
\text { braking force [ \%] }\end{array}$ & for front axle $\mathrm{K}_{\mathrm{b} 1}$ & 72.1 & 68.2 & 64.4 & 60.6 & 56.7 \\
\cline { 2 - 7 } & for rear axle $\mathrm{K}_{\mathrm{b} 2}$ & 27.9 & 31.8 & 35.6 & 39.4 & 43.3 \\
\hline
\end{tabular}

Table 5. Change in the magnitude of the braking force (in percentage) at the front and rear axles depending on the height of the $\mathrm{CG}$ above the flat road surface using $\mu \mathrm{x}=0.8$ and $\mathrm{f}=0.011$

\begin{tabular}{|c|c|c|c|c|c|c|}
\hline \multirow{3}{*}{$\begin{array}{l}\text { Distance of center of gravity } \\
\text { [m] }\end{array}$} & from the front axle $L_{1}$ & \multicolumn{5}{|c|}{1.2} \\
\hline & from the rear axle $L_{2}$ & \multicolumn{5}{|c|}{1.4} \\
\hline & above the flat road surface $h_{t}$ & 0.6 & 0.65 & 0.7 & 0.75 & 0.8 \\
\hline \multirow{2}{*}{$\begin{array}{l}\text { Percentage from the total } \\
\text { braking force [ } \%]\end{array}$} & for front axle $K_{b 1}$ & 72.6 & 74.1 & 75.7 & 77.2 & 78.8 \\
\hline & for rear axle $\mathrm{K}_{\mathrm{b} 2}$ & 27.4 & 25.9 & 24.3 & 22.8 & 21.2 \\
\hline
\end{tabular}

Table 6. Typical values of the adhesion coefficient of automobile tire depending on the surface

\begin{tabular}{|c|c|c|c|c|c|c|c|c|c|}
\hline Surface & $\begin{array}{c}\text { Dry } \\
\text { concrete }\end{array}$ & $\begin{array}{c}\text { Dry } \\
\text { asphalt }\end{array}$ & $\begin{array}{c}\text { Wet } \\
\text { concrete }\end{array}$ & $\begin{array}{c}\text { Wet } \\
\text { asphalt }\end{array}$ & $\begin{array}{c}\text { Dry } \\
\text { pavement }\end{array}$ & $\begin{array}{c}\text { Wet } \\
\text { pavement }\end{array}$ & $\begin{array}{c}\text { Muddy } \\
\text { surface }\end{array}$ & $\begin{array}{c}\text { Packed } \\
\text { snow }\end{array}$ & $\begin{array}{c}\text { Melting } \\
\text { ice }\end{array}$ \\
\hline$\mu$ & 1.0 & 0.9 & 0.7 & 0.6 & 0.5 & 0.4 & 0.3 & 0.3 & 0.1 \\
\hline
\end{tabular}


Table 7. Change of the braking force percentage on front and rear axles depending on the adhesion coefficients for different surfaces using $\mathrm{f}=0.011$

\begin{tabular}{|c|c|c|c|c|c|c|c|c|c|}
\hline \multirow{3}{*}{$\begin{array}{l}\text { Distance of center of } \\
\text { gravity [m] }\end{array}$} & $\begin{array}{l}\text { from the front } \\
\text { axle } L_{1}\end{array}$ & \multicolumn{8}{|c|}{1.2} \\
\hline & $\begin{array}{l}\text { from the rear } \\
\text { axle } L_{2}\end{array}$ & \multicolumn{8}{|c|}{1.4} \\
\hline & $\begin{array}{l}\text { above the flat road } \\
\text { surface } h_{t}\end{array}$ & \multicolumn{8}{|c|}{0.7} \\
\hline$\mu$ & & 1 & 0.9 & 0.7 & 0.6 & 0.5 & 0.4 & 0.3 & 0.1 \\
\hline \multirow{2}{*}{$\begin{array}{l}\text { Percentage from the } \\
\text { total braking force [\%] }\end{array}$} & for front axle $\mathrm{K}_{\mathrm{b} 1}$ & 81.1 & 78.4 & 73.0 & 70.3 & 67.6 & 64.9 & 62.2 & 56.8 \\
\hline & for rear axle $\mathrm{K}_{\mathrm{b} 2}$ & 18.9 & 21.6 & 27.0 & 29.7 & 32.4 & 35.1 & 37.8 & 43.2 \\
\hline
\end{tabular}

\section{CONCLUSIONS}

Vehicle load causes changes in the center of gravity position. Displacement of the center of gravity affects the driving characteristics of the vehicle. The increase in the height of the center of gravity is reflected in the reduction of the maximum speed when cornering or in the need of increasing the road curve radius. Load of the passenger vehicle reduces the maximum speed by average of $5 \mathrm{kmph}$ when passing the road curve section. In case of a truck the vehicle payload is comparable to the vehicle weight, which causes a significant increase in height of the center of gravity when loaded in comparison with a passenger vehicle. The average reduction of speed rate needed for safe cornering achieves in this case the value of $27.9 \mathrm{kmph}$.

Displacement of the CG of vehicle has an effect on vehicle axles load distribution as well. Axle load determines the maximum of braking force as well as the adhesion coefficient of tires. In modern vehicles an adverse effect of different axle loads and thus the individual wheels is eliminated by electronic brakeforce distribution system (EBD).

\section{REFERENCES}

1. Barta, D. at all. Vehicle tire pressure monitoring systems. Diagnostyka, 15,2014, 11-14.

2. Caban, J. at all. Studies on operational wear of glycol-based brake fluid. Przemysl chemiczny 94, 2015, 1802-1806.

3. Caban, J. at all. The research on ageing of glycolbased brake fluids of vehicles in operation. Advances in science and technology-reseach journal, 10, 2016, 9-16.

4. Drozdziel, P. at all. The engine set damage assessment in the public transport vehicles. Advance in science and technology 11 (1), 2017, 117-127
5. Drozdziel, P. at all. Selected aspects of analyses of failure rates of active safety systems in buses. Komunikacie 16, 2014, 114-119.

6. Figlus, T. Possibility to control and adjust the suspensions of vehicles. Activites of transport telematics 395, 2013, 378-383

7. Jagelčák, J - Zámečník, J. Evaluation of wagon impact tests by various measuring equipment and influence of impacts on Cargo stability. Komunikacie 17, 2015, 21-27

8. Jagelčák, J. at all. Comparison of acceleration acting on cargo in front and in rear part of semi-trailer during braking with and without using the systems abs/ebs. Komunikacie 18. 2016, 76-82

9. Janoško, I. at all. System for monitoring operating parameter of vehicles. Proc. on 5 th. Conference TAE, Prague, Czech republic, 2013, 267 - 272

10. Jaskiewicz, M. at all. Driver's reaction time under emergency braking a car - research in a driving simulator. Eksploatacja i Niezawodność 14 (4), 2012, 295-301.

11. Kalašová, A. at all. The impact of intelligent transport systems on an accident rate of the chosen part of road communication network in the Slovak republic. Proc. on 16th International Conference on Transport Systems Telematics, Katowice, Poland 2016, 47-58.

12. Kalašová, A. at all. A new approach to road safety in Slovakia. Telematics in transport environment, 329, 2012, $388-395$

13. Kalašová, A - Kapusta, J. Motor vehicle safety technologies in relation to the accident rates. Proc. on 15th International Conference on Transport Systems Telematics, Wroclaw, Poland 2015, 172-179.

14. Kendra, M. at all. Changes of the infrastructure and operation parameters of a railway line and their impact to the track capacity and the volume of transported goods. Transport research arena 48, 2012, $743-752$

15. Konieczny, L. at all. Non-conventional suspension systems in heavy special-purpose trucks. Vibroengineering procedia $6.2015,254-258$

16. Konieczny, L. at all. 2012. The influence of chang- 
ing vehicle tire stiffness on phase angle. Proc. on 19th International Congress on Sound and Vibration, Vilnius, Lithuania 2012, 2844-2851.

17. Krzywonos, L. at all. Using of non-conventional fuels in hybrid vehicle drivers. Advance in science and technology 10, 2016, 240-247.

18. Liščák, S - Olejnik, K. Criticism of the european regulations with an aim to increase haulage capability of the road train. Transport means. 66-169.

19. Močkoř, R.: Stavba motorových vozidiel I. čast': Podvozkové časti automobilov, SVŠT Bratislava, 1990.

20. Močkoř, R.: Motorové vozidlá II, podvozkové orgány, STU Bratislava, 1990.

21. Rievaj, V. at all. The impact of air resistance on the fuel consumption in real conditions within the transport operation. Komunikacie 18, 2016, 57-61.

22. Rievaj, V. at all. Automobil a jeho dynamika. Žilinská univerzita v Žiline 2013.

23. Rievaj, V. - Vrábel, J. - Ondruš, J. Cestné vozidlá - návody na cvičenia. Žilina: Edis 2014.

24. Skrúcaný, T-Gnap, J. The effect of the crosswinds on the stability of the moving vehicles, Applied mechanics And materials. 617, 2014, 296-301.

25. Stopka, O. at all. The significance of dynamic detection of the railway vehicles weight. Nase more, 63, 2016 Pages: 156-160.

26. Sarkan, B. at all. Measuring the resistance of tires for passenger vehicle against the rolling and sliding on loading area of the flatbed truck when providing the transport services. Komunikacie, 18, 2016, 124-128. 